\title{
Raciocínio Matemático nos Primeiros Anos: ações de duas professoras ao discutir tarefas com seus alunos
}

\author{
Mathematical Reasoning in Elementary School: actions of two teachers \\ when discussing tasks with their students
}

\author{
Eliane Maria de Oliveira Araman * \\ ORCID iD 0000-0002-1808-2599 \\ Maria de Lurdes Serrazina ${ }^{* *}$ \\ ORCID iD 0000-0003-3781-8108 \\ João Pedro da Ponte ${ }^{* * *}$ \\ ORCID iD 0000-0001-6203-7616
}

\begin{abstract}
Resumo
Este artigo apresenta resultados de uma investigação sobre o raciocínio matemático, mais especificamente sobre as ações de professores que o potencializam. O objetivo foi identificar, categorizar e discutir as ações efetuadas por duas professoras durante a discussão de tarefas exploratórias realizadas em duas turmas do $1^{\circ}$ Ciclo de Ensino Básico ${ }^{1}$, uma do $1^{\circ}$ ano e outra do $3^{\circ}$ ano, de uma escola pública da periferia de Lisboa. Os dados foram coletados por meio de observação participante suportada por gravação em áudio e vídeo das aulas. Após a transcrição, os dados foram analisados em quatro categorias de ações de professores, a saber: convidar; guiar/apoiar; informar/sugerir e desafiar. Por meio da análise, ressaltamos que as ações efetuadas pelas professoras durante a discussão das tarefas favoreceram os processos de conjecturar, comparar, identificar padrões e justificar dos alunos. Os resultados alcançados por este estudo trazem evidências da relevância que as ações dos professores têm para o desenvolvimento do raciocínio matemático desde os primeiros anos.
\end{abstract}

Palavras-chave: Raciocínio Matemático. Ações do professor. Processos de Raciocínio. $1^{\circ}$ Ciclo do Ensino Básico.

\footnotetext{
* Doutora em Ensino de Ciências e Educação Matemática pela Universidade Estadual de Londrina (UEL). Professora do Departamento de Matemática e do Programa de Pós-Graduação em Ensino de Matemática da Universidade Tecnológica Federal do Paraná (UTFPR), Cornélio Procópio, Paraná, Brasil. Endereço para correspondência: Av. Alberto Carazzai, 1640, Cornélio Procópio, Paraná, Brasil, CEP: 86300-000. E-mail: elianearaman@utfpr.edu.br.

** Doutora em Educação Matemática pela Universidade de Londres (UK). Professora Coordenadora Aposentada da Escola Superior de Educação do Instituto Politécnico de Lisboa, Lisboa, Portugal. Membro integrado da Unidade de Investigação e Desenvolvimento em Educação e Formação (UIDEF), do Instituto de Educação, Universidade de Lisboa, Portugal. Endereço para correspondência: Campus de Benfica do IPL, Lisboa, Portugal, CEP: 1549-003. E-mail: lurdess@eselx.ipl.pt.

*** Doutor em Educação Matemática pela Universidade da Georgia. EUA (UGA). Professor catedrático do Instituto de Educação, Universidade de Lisboa (IE-ULisboa), Lisboa, Portugal. Endereço para correspondência: Alameda da Universidade, Lisboa, Portugal, CEP: 1649-013. Email: jpponte@ie.ulisboa.pt.

${ }^{1}$ Em Portugal, o Ensino Básico é composto por três Ciclos. O $1^{\circ}$ Ciclo compreende os $1^{\circ}, 2^{\circ}, 3^{\circ}$ e $4^{\circ}$ anos; o $2^{\circ}$

Cilco compreende os $5^{\circ}$ e $6^{\circ}$ anos e o $3^{\circ}$ Ciclo compreende os $7^{\circ}, 8^{\circ}$ e $9^{\circ}$ anos de escolarização.
} 


\begin{abstract}
This paper presents the results of an investigation into mathematical reasoning, specifically about the actions of teachers to enhance it. The objective was to identify, categorize, and discuss the actions performed by two teachers during the discussion of exploratory tasks solved in two classes of the $1^{\text {st }}$ Cycle of Basic Education, a ${ }^{\text {st }}$ grade and a $3^{\text {rd }}$ grade class of a public school near Lisbon. Data were collected through participant observation supported by audio and video recording of the classes. After transcription, data were analyzed in four categories of teacher actions: invite; guide/support; inform/suggest, and challenge. Data analysis concerns that the actions carried out by the teachers in whole-class discussions favored the student's processes of conjecture formulation, comparison, identification of patterns, and justification. The results achieved by this study provide evidence to the relevance of the teachers' actions for the development of mathematical reasoning since the early years.
\end{abstract}

Keywords: Mathematical reasoning. Teacher Actions. Reasoning Processes. $1^{\text {st }}$ Cycle of Basic Education.

\title{
1 Introdução
}

O desenvolvimento do raciocínio matemático é discutido, por muitos pesquisadores, como um dos grandes objetivos do ensino da Matemática (JEANNOTTE; KIERAN, 2017, MATA-PEREIRA; PONTE, 2018, STYLIANIDES, 2009). Em termos curriculares, o raciocínio matemático também merece destaque (NCTM, 2009), desde o início da escolarização, constituindo um processo central na aprendizagem matemática desde a infância (BRUNHEIRA; PONTE, 2019). Na concretização destas orientações o trabalho do professor é, naturalmente, fundamental.

Deste modo, é importante discutir as ações dos professores e o respectivo papel para a promoção do raciocínio matemático dos alunos (ELLIS; ÖZGÜR; REITEN, 2018; PONTE; QUARESMA, 2016). Assim, o presente artigo tem como objetivo identificar, categorizar e discutir as ações realizadas por duas professoras dos primeiros anos ao conduzir discussões sobre tarefas exploratórias na sala de aula e como tais ações potencializam os processos de raciocínio matemático em seus alunos.

\section{Raciocínio matemático e seus processos}

Para Jeannotte e Kieran (2017, p. 7), o raciocínio matemático pode ser entendido "como um processo de comunicação com outros ou consigo mesmo que permite inferir enunciados matemáticos a partir de outros enunciados matemáticos”. Stylianides (2009) apresenta uma definição convergente ao considerar o raciocínio matemático como um processo de inferência que utiliza informação matemática já conhecida para obter novo conhecimento ou novas conclusões. Também Mata-Pereira e Ponte (2018) formulam uma definição semelhante, assumindo que raciocinar matematicamente é fazer inferências justificadas, ou seja, "utilizar informação já conhecida para obter, justificadamente, novas 
conclusões" (MATA-PEREIRA; PONTE, 2018, p. 782). Estes autores indicam que "os processos de raciocínio matemático incluem formular questões e estratégias de resolução, formular e testar generalizações e outras conjecturas e justificá-las" (MATA-PEREIRA; PONTE, 2017, p. 2). Pelo seu lado, Lannin, Ellis e Elliot (2011) compreendem o raciocínio matemático como o processo conjunto de conjecturar, generalizar, investigar porquê, argumentar e refutar se necessário.

Jeannotte e Kieran (2017) identificaram dois aspectos do raciocínio matemático: a estrutura e o processo. As formas da estrutura são a dedução, a indução e a abdução. No que se refere aos processos de raciocínio, Jeannotte e Kieran (2017) identificaram oito processos. Estes processos incluem a procura de semelhanças e diferenças, envolvendo generalizar, conjecturar, identificar um padrão, comparar e classificar; os processos relativos à validação são justificar e provar; e a exemplificação, que dá suporte aos outros processos. A estrutura e o processo são dois modos de olhar para o raciocínio matemático que se relacionam, já que as “estruturas são parte do aspecto de processo do raciocínio matemático e os processos contribuem para a construção dessas estruturas" (JEANNOTTE; KIERAN, 2017, p. 7).

O processo generalizar pressupõe que se infiram narrativas sobre um conjunto de objetos matemáticos ou sobre as relações entre os elementos desse conjunto. Para Lannin, Ellis e Elliot (2011), os alunos generalizam quando se focam numa ideia ou num aspecto particular de um problema e pensam nele de uma forma abrangente. De modo semelhante, Ponte, Mata-Pereira e Henriques (2012, p. 3) afirmam que a generalização "parte de uma conclusão ou conjetura específica para formular uma conjetura de âmbito mais geral”.

Para Morais, Serrazina e Ponte (2018, p. 555), conjecturar consiste em "um processo que envolve raciocínio sobre relações matemáticas, desenvolvendo declarações, nomeadas como conjeturas, que requerem maior exploração para verificar se são verdadeiras ou não verdadeiras". Conjecturar envolve um processo cíclico de: (i) enunciar a conjectura; (ii) verificar se cobre todos os casos e exemplos; (iii) tentar refutar; e (iv) encontrar um motivo que faça com que a conjectura seja verdadeira ou tentar modificá-la (JEANNOTTE; KIERAN, 2017).

De acordo com Lannin, Ellis e Elliott (2011), os alunos podem criar conjecturas válidas ou inválidas, apoiadas em raciocínios válidos ou, por vezes, inválidos. Embora não sejam desejáveis, os raciocínios inválidos podem servir de ponto de partida para o entendimento de ideias matemáticas. Uma conjectura pode ser escrita de várias formas, ou até mesmo existir apenas na mente dos alunos. Em contexto escolar, os alunos procuram regularmente padrões e relações e procuram entender porque eles existem (LANNIN; ELLIS; 
ELLIOTT, 2011). O processo de identificar padrões pode ser confundido com conjecturar, sendo que identificar padrões pode levar a uma conjectura, contudo, os dois processos não são iguais (STYLIANIDES, 2009).

A comparação é um processo que procura, por meio da percepção de semelhanças e diferenças, construir uma narrativa sobre objetos ou relações matemáticas. O processo de comparar pode ocorrer com outros processos de raciocínio matemático como generalizar, identificar um padrão ou validar (JEANNOTTE; KIERAN, 2017). Já a classificação pode ser entendida como um processo que procura justificar conjecturas de forma objetiva, tendo como base propriedades e definições matemáticas (JEANNOTTE; KIERAN, 2017).

Segundo Jeannotte e Kieran (2017), a validação é um processo matemático cujo objetivo é alterar o valor epistêmico de uma narrativa e pode ser feita de três formas, justificar, provar e provar formalmente. Para as autoras, "justificar é um processo de procura de dados, afirmações e suporte para modificar o valor epistêmico. Justificar é um processo social, podendo assumir dois formatos: (i) justificar a conjectura que surgiu no processo e (2) relatar a validade que altera o valor epistêmico" (JEANNOTTE; KIERAN, 2017, p. 12). O processo de justificar, para além de mostrar que uma afirmação é verdadeira, fornece razões pelas quais ela é verdadeira ou válida em todos os casos possíveis.

Provar e provar formalmente (cujo rigor e grau de formalismo é maior do que em provar) também são processos sociais usados pelos indivíduos ou pela comunidade para responder a questões da veracidade de uma afirmação. Provar algo é um tipo especial de atividade matemática na qual os indivíduos tentam justificar as suas afirmações por meio de uma argumentação dedutiva. De acordo com Jeannotte e Kieran (2017), este processo altera o valor epistêmico de provável para verdadeiro, através da pesquisa de dados, enunciados ou algo que suporte essa alteração.

O processo de exemplificar apoia os demais, uma vez que infere exemplos que apoiam tanto a pesquisa de semelhanças e diferenças como a validação. Este processo permite explorar problemas com o objetivo de conjecturar, verificar as conjecturas e reformulá-las ou pode levar a generalizações (JEANNOTTE; KIERAN, 2017).

Para Morais, Serrazina e Ponte (2018, p. 556), "alunos de diferentes anos escolares podem se envolver em processos de raciocínio matemático". Assim, as formas pelas quais os processos de raciocínio matemático são apresentados podem assumir diferentes modos ao longo da escolaridade. Neste artigo, analisamos os processos de raciocínio matemático trabalhados por alunos do $1^{\circ}$ e do $3^{\circ}$ ano de escolaridade, bem como as ações dos professores que os potencializam. 


\section{Ações de professores que apoiam o raciocínio matemático}

Nos últimos anos, o raciocínio matemático tem sido considerado como importante vertente transversal no ensino de Matemática, desde que aliado à realização de tarefas desafiantes e discussões coletivas com a turma acerca da sua resolução (PONTE; MATAPEREIRA; QUARESMA, 2013). O modo de promover o raciocínio matemático dos alunos é uma questão importante a ser investigada e as ações desempenhadas pelo professor ocupam um papel central na promoção do raciocínio matemático dos alunos (MATA-PEREIRA; PONTE, 2018).

Segundo o NCTM (2009), uma das ações fundamentais que precisam ser consideradas pelos professores para promover o raciocínio matemático nos seus alunos é o questionamento. Como indicam Mata-Pereira e Ponte (2018, p. 758), “Se as perguntas são habitualmente mais provocatórias, os alunos esperam ter que dar respostas mais complexas e que envolvam processos de raciocínio". Por sua vez, Wood (1997) considera que diferentes interações, seja entre alunos, seja entre estes e o professor, criam diferentes contextos de aprendizagem. As ações do professor precisam garantir oportunidades de interação, uma vez que "as aulas onde os alunos expressam os seus pensamentos, explicando-os e justificando-os, constituem ambientes propícios ao desenvolvimento do seu raciocínio matemático" (ARAMAN; SERRAZINA; PONTE, 2019, p. 470).

Ellis, Özgür e Reiten (2018, p. 2) consideram que, para apoiar a aprendizagem dos alunos, "as discussões em sala de aula devem concentrar-se tanto em ideias matemáticas importantes quanto no desenvolvimento de significados matemáticos por meio de processos comunicativos". O papel desempenhado pelo professor em tais discussões é fundamental e vai desde selecionar tarefas apropriadas, definir sobre, quando e como estimular o pensamento dos alunos, até incentivar que estes assumam a responsabilidade intelectual de construir e defender suas ideias matemáticas.

Ponte, Mata-Pereira e Quaresma (2013) estudaram as ações dos professores que promovem o raciocínio matemático e organizaram-nas em quatro categorias: ações de Convidar, quando os professores fazem questões com a finalidade de inserir os alunos no contexto de discussão; ações de Guiar/Apoiar, em que os professores conduzem os alunos a fornecerem explicações sobre como estão a pensar; ações de Informar/Sugerir, quando os professores fornecem informações, sugestões, explicações que apoiam o raciocínio dos alunos; e ações de Desafiar, nas quais os professores desafiam os alunos a estenderem o seu raciocínio matemático, colocando-os na situação de serem eles próprios a avançarem em 
terrenos novos, "seja em termos de representações, da interpretação de enunciados, do estabelecimento de conexões, ou de raciocinar, argumentar ou avaliar" (PONTE; MATAPEREIRA; QUARESMA, 2013, p. 59).

Araman, Serrazina e Ponte (2019), tendo por base modelos de ações de professores apresentados e discutidos por Wood (1997), Ponte, Mata-Pereira e Quaresma (2013) e Ellis, Özgür e Reiten (2018), organizaram quatro categorias de ações que apoiam o raciocínio matemático (ARAMAN; SERRAZINA; PONTE, 2019), conforme consta no Quadro 1. As categorias estão nomeadas de acordo com Ponte, Mata-Pereira e Quaresma (2013).

\begin{tabular}{|c|c|c|c|}
\hline \multirow{4}{*}{$\begin{array}{c}\mathrm{C} \\
\mathrm{A} \\
\mathrm{T} \\
\mathrm{E} \\
\mathrm{G} \\
\mathrm{O} \\
\mathrm{R} \\
\mathrm{I} \\
\mathrm{A} \\
\mathrm{S}\end{array}$} & Convidar & $\begin{array}{l}\text { - Solicita respostas para questões pontuais. } \\
\text { - Solicita relatos de como os alunos fizeram. }\end{array}$ & \\
\hline & Guiar/Apoiar & $\begin{array}{l}\text { - Fornece pistas aos alunos. } \\
\text { - Incentiva a explicação. } \\
\text { - Conduz o pensamento do aluno. } \\
\text { - Focaliza o pensamento do aluno para fatos importantes. } \\
\text { - Encoraja os alunos a (re)dizerem suas respostas. } \\
\text { - Encoraja os alunos a (re)elaborarem suas respostas. }\end{array}$ & $\begin{array}{l}\text { A } \\
\text { Ç }\end{array}$ \\
\hline & Informar/Sugerir & $\begin{array}{l}\text { - Valida respostas corretas fornecidas pelos alunos. } \\
\text { - Corrige respostas incorretas fornecidas pelos alunos. } \\
\text { - (Re)elabora respostas fornecidas pelos alunos. } \\
\text { - Fornece informações e explicações. } \\
\text { - Incentiva e fornece múltiplas estratégias de resolução. }\end{array}$ & $\begin{array}{l}\tilde{\mathrm{O}} \\
\mathrm{E}\end{array}$ \\
\hline & Desafiar & $\begin{array}{l}\text { - Solicita que os alunos apresentem razões (justificativas). } \\
\text { - Propõe desafios. } \\
\text { - Encoraja a avaliação. } \\
\text { - Encoraja a reflexão. } \\
\text { - Pressiona para a precisão. } \\
\text { - Pressiona para a generalização. }\end{array}$ & $\mathrm{S}$ \\
\hline
\end{tabular}

Assumimos, neste estudo, que na categoria Convidar estão as ações pelas quais o professor "solicita informações dos alunos, seja por meio de questões diretas, ou por meio de explicações para o que fez tendo como objeto observar como os alunos estão pensando e qual a sua compreensão a respeito daquele tema" (ARAMAN; SERRAZINA; PONTE, 2019, p. 476).

Guiar/Apoiar abarca as ações em que o professor, "a partir de perguntas ou explicações, conduz o pensamento do aluno para uma determinada situação ou focaliza fatos importantes ou ainda quando o professor fornece pistas aos alunos e os encoraja a pensarem sobre suas respostas" (ARAMAN; SERRAZINA; PONTE, 2019, p. 476). Informar/Sugerir inclui as ações em que o professor reage às informações fornecidas pelos alunos, seja por meio da validação ou correção de uma resposta ou reelaborando uma informação dada pelos alunos, mas que esteja incompleta ou que precisa ser aprimorada. Também inclui as ações de fornecer explicações e informações e solicitar ou apresentar outras estratégias de resolução 
(ARAMAN; SERRAZINA; PONTE, 2019).

As ações de Desafiar são aquelas nas quais o professor "tenta colocar os alunos em situação desafiadora de modo que estes avancem em seu raciocínio matemático, procurando novas formas de representação, estabelecendo novas conexões, refletindo e avaliando a situação, generalizando e justificando" (ARAMAN; SERRAZINA; PONTE, 2019, p. 476). Destacamos que, embora as categorias sejam apresentadas em uma certa ordem, não existe obrigatoriedade de sequência entre elas nem de hierarquização. As ações desempenhadas pelos professores não precisam ocorrer necessariamente em todas as interações, sendo necessário destacar que algumas delas apresentam maior potencial para apoiar o raciocínio.

\section{Metodologia}

O presente estudo analisa as ações realizadas por duas professoras do $1^{\circ}$ Ciclo do Ensino Básico ao conduzirem discussões coletivas em sala de aula durante a realização de tarefas matemáticas de caráter exploratório. Esta investigação segue uma abordagem qualitativa com caráter interpretativo e insere-se num projeto mais amplo que utiliza uma metodologia de investigação baseada em design (COBB; JACKSON; DUNLOP, 2016; PONTE et al., 2016).

Foram analisadas duas aulas, uma do $1^{\circ}$ ano e outra do $3^{\circ}$ ano, lecionadas por duas professoras diferentes de uma escola pública da periferia de Lisboa. As aulas foram gravadas em áudio/vídeo e posteriormente transcritas. Os nomes dos alunos e das professoras foram alterados com a finalidade de garantir a confidencialidade. A resolução da tarefa 1 ocorreu em março de 2015 em uma turma de $1^{\circ}$ ano composta por 26 alunos. A tarefa realizada na aula tinha o objetivo de desenvolver a flexibilidade de cálculo em problemas de adição (Figura 1).

\section{Comparar}

0 que a rapariga ganha perde para o rapaz. 0 que o rapaz ganha perde para a rapariga. Descreve com números o que se passa ao longo do jogo.
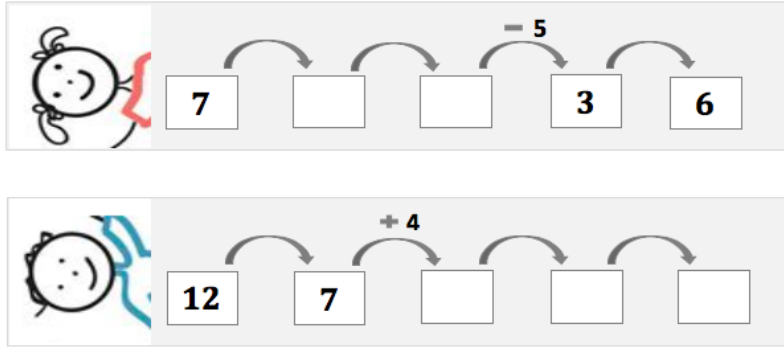

Quem é que ao longo do jogo ganhou mais pontos? Quem é o melhor jogador?

Figura 1 - Tarefa realizada no $1 .^{\circ}$ ano

Fonte: Tarefa construída por Jean-Marie Kraemer para o projeto Pensamento numérico e cálculo flexivel. 
A tarefa 2 foi realizada em março de 2016 em uma turma de $3 .^{\circ}$ ano composta, também, por 26 alunos. A tarefa realizada na aula era composta por duas partes e tinha o objetivo de desenvolver a flexibilidade de cálculo em problemas de multiplicação (Figura 2).

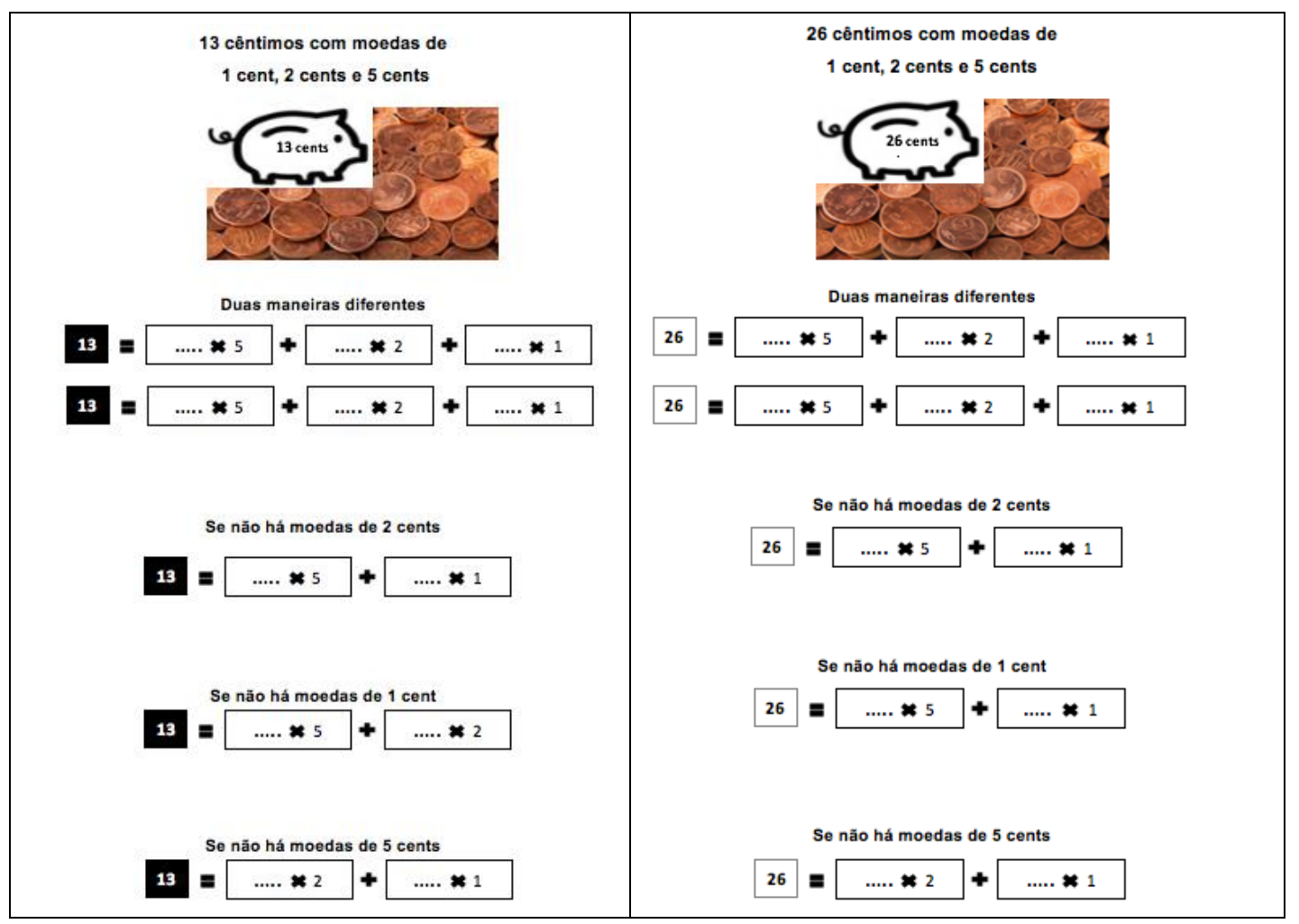

Figura 2 - Tarefa realizada no $3 .^{\circ}$ ano

Fonte: Tarefa construída por Jean-Marie Kraemer para o projeto Pensamento numérico e cálculo flexivel.

Em ambas as turmas os alunos trabalharam primeiro autonomamente na realização das tarefas, organizados em pares, o que permitiu o intercâmbio de ideias entre eles, fazendo registros escritos individuais na folha de resolução. Após esse momento, os pares foram convidados à lousa para apresentar sua resolução. Estes momentos suscitaram discussões conduzidas pelas professoras e o foco da análise está nas suas ações ao longo das discussões coletivas. Para a análise, consideramos quatro categorias de ações organizadas a partir da síntese dos modelos sobre as ações dos professores que apoiam o raciocínio matemático (ARAMAN; SERRAZINA; PONTE, 2019), conforme consta no Quadro 2.

\section{Resultados}

\subsection{Turma do $1 .^{\circ}$ ano - Tarefa 1}

A professora reproduz a tarefa (Figura 1) no quadro. Vão duas crianças ao quadro 
(Paulo e Mônica) e apresentam a resolução (Figura 3), de acordo com o que fizeram durante a exploração autônoma em pares.

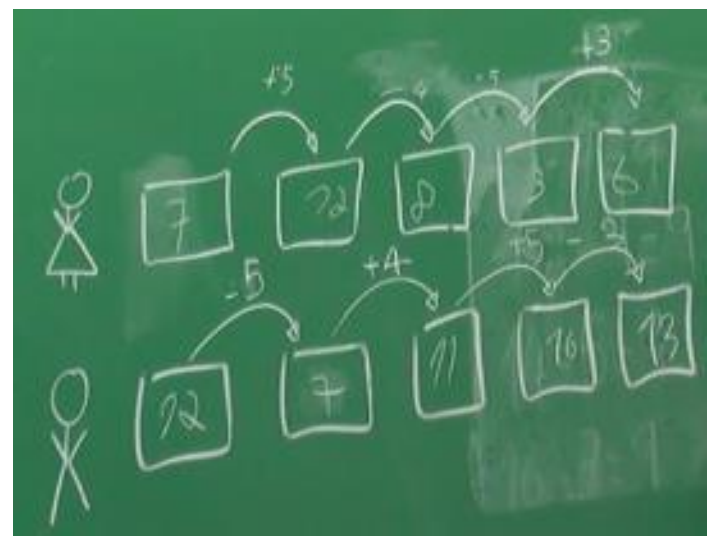

Figura 3 - Registros feitos por Paulo e Mônica Fonte: Dados da pesquisa.

Neste momento, todas as ações desempenhadas pela professora se enquadram em Convidar. O seu objetivo é iniciar os alunos na discussão, solicitando que eles relatem como resolveram a tarefa ou fazendo perguntas pontuais ("E o debaixo? Se a rapariga ganhou mais 5 o que aconteceu com o rapaz?" (Transcrição da fala da professora, ano). Embora possa parecer, num primeiro momento, que tais ações não apoiam o raciocínio matemático, elas são fundamentais para subsidiar as ações das demais categorias. Após o término da explicação feita por Paulo e Mônica, a professora retoma a discussão, colocando uma questão nova aos alunos:

Professora: Quem é que ficou com mais berlindes?(Convidar)

Alunos: O rapaz.

Professora: Mas o rapaz começou com mais ou com menos?(Guiar)

[Vários alunos se manifestam, no que a professora solicita que fale um de cada vez].

Professora: Fala Dario.

Dario: Esses números [indica os números 7 e 12 da rapariga e 12 e 7 do rapaz], já repararam que fazendo um xisinho $(x)$ eles são iguais?

Professora: Por que será que isso acontece? (Desafiar) Aqui acontece isso? [indica outros números da tarefa] (Guiar/Apoiar)

Alunos: Não.

Professora: Por que acontece aqui isto? [volta a indicar o 7 e o 12] (Desafiar)

Dario: Porque 7 mais 5 são 12 e 12 menos 5 dá 7.

Professora: Maria, quer ajudar o Dario? Explica lá Maria. (Desafiar)

Maria: Porque o número que o menino tinha foi o número que a rapariga ganhou.

Professora: Aqui tinha o 12 que é o número que vocês tinham registrado na folha. O rapaz perdeu 5 e ficou com 7. [indica o número 7 do rapaz]. Se aqui tinha 7 [indica o número 7 da rapariga]. (Guiar)

Paulo: A rapariga tinha o número que o rapaz ficou.

Professora: E a rapariga acabou por ficar... (Guiar)

Paulo: Com o número que o rapaz tinha no início.

Professora: A rapariga ficou com o número que o rapaz tinha no início [indica o número 12 do rapaz e o 12 da rapariga]. (Informar/Sugerir).

(Transcrição do diálogo entre a professoras e os alunos, 2015). 
Este trecho apresenta ações da professora nas quatro categorias. Ela retoma a discussão colocando aos alunos questões pontuais, ações de Convidar, que vão subsidiar as demais questões feitas por ela ao longo da discussão. Em seguida, o aluno Dario observa uma regularidade e a relata para a professora. Na sequência, ela faz um questionamento (Por que será que isso acontece?) para que os alunos apresentem razões, ou seja, apresentem justificativas para o que observaram. Questionamentos desse tipo se enquadram em Desafiar. Ao responder ao desafio da professora, Dario apresenta a sua justificativa. A professora também realiza ações de Guiar/Apoiar, solicitando aos alunos que observem, nos demais números da sequência, se aquela regularidade se mantém. Por fim, a professora auxilia o aluno a elaborar sua resposta e a valida, repetindo-a para toda a turma. Deste modo, neste diálogo, os alunos identificam um padrão e apresentam justificativas.

A professora retoma a questão de quem ficou com mais berlindes:

Professora: Vocês me disseram que quem ficou com mais foi o rapaz. (Informar/Sugerir) Alunos: Sim.

Professora: Mas o rapaz também começou com mais. (Informar/Sugerir)

Alice: Sim, começou com mais e ganhou com mais.

Professora: Começou com mais e acabou com mais [indica o número 12 e o número 13 do rapaz] (Informar/Sugerir). Agora a minha pergunta é: no final, quantos berlindes é que, nestas jogadas, quantas jogadas? Daqui para aqui uma [vai indicando as jogadas]. (Guiar/Apoiar)

Alunos: Duas, três, quatro.

Professora: Quantas jogadas? (Guiar/Apoiar)

Alunos: Quatro.

Professora: Quatro. (Informar/Sugerir) Ao todo aqui na rapariga, quantos berlindes é que ela ganhou e quantos é que ela perdeu? (Guiar/Apoiar)

[Os alunos pensam um pouco]

Dario: Professora, ela ganhou 8.

Professora: Ela ganhou 8. (Informar/Sugerir) Como é que eu escrevo isso, ganhou 8, com símbolos matemáticos? (Desafiar)

[Os alunos pensam um pouco].

Professora: Como é que que escrevo que ela ganhou 8? (Desafiar)

Lara: Um mais e um 8.

Professora: Ganhou 8 [anota no quadro +8 ] (Informar/Sugerir). Quantos que ela perdeu?

[Os alunos se alvoroçam e falam ao mesmo tempo, a professora organiza a turma].

Professora: Ela perdeu 4 uma vez [indica o -4] e aqui, perdeu ou ganhou [indica o -5]?

(Guiar/Apoiar)

Alunos: Perdeu.

Professora: Quantos é que ela perdeu? (Guiar/Apoiar)

Alunos: Nove.

Dario: Menos 9. (Informar/Sugerir)

[A professora anota -9 no quadro].

(Transcrição do diálogo entre a professoras e os alunos, 2015)

Neste trecho, as ações da professora estão distribuídas em três categorias. As ações de Guiar/Apoiar têm o objetivo de conduzir e focalizar o pensamento dos alunos para aspectos 
importantes da discussão, como, por exemplo, quando ela focaliza a atenção no número de jogadas e na quantidade de berlindes que a menina ganhou e perdeu. Importante notar que há todo um esforço por parte da professora para que os alunos consigam responder aos seus questionamentos. Embora não haja um processo de raciocínio matemático explícito por parte dos alunos, a professora tenta que eles justifiquem porque a rapariga, ao longo de todas as jogadas, acaba por perder 1. Os questionamentos feitos pela professora levam à formulação de uma estratégia de resolução, de forma que os alunos que conseguiram resolver a questão vão dando indicações de como o fizeram, construindo um resultado final. A justificativa acaba sendo construída a partir do diálogo, iniciado neste trecho e continuado nos demais.

Também há momentos em que a professora valida e repete as respostas corretas dadas pelos alunos e fornece informações, ações de Informar/Sugerir. Com relação as ações de Desafiar, a professora pressiona os alunos para a precisão, ao desafiá-los a escreverem "ganhou 8" com "símbolos matemáticos".

A discussão continua:

Professora: No final de tudo ela acabou por ganhar ou perder? (Desafiar)

Alunos: Perder.

Professora: Quantos? (Desafiar)

[Os alunos não respondem.]

Professora: Ela ganhou 8 [indica o +8 ] e perdeu 9 [indica o -9]. (Guiar/Apoiar)

Lucas: Acabou por perder 9.

Professora: Mas ela ganhou 8. (Guiar/Apoiar) Como é que ficou no final? (Desafiar)

Lucas: 09 é maior do que 8.

Professora: $O 9$ é maior do que 8 (Informar/Sugerir). Ela ficou a perder ou a ganhar? (Desafiar)

Alunos: A perder.

Professora: Quantos? (Desafiar)

Gabriel: Se o 9 é maior do que o 8, ela tinha que ficar com 0.

Professora: Ela perdeu 9, mas ganhou 8 (Informar/Sugerir).

Miguel: Ficou com 1.

Professora: Quem disse que ficava com 1? (Informar/Sugerir).

Alunos: O Miguel.

Professora: Mas no final de tudo, ela perde ou ganha?

Alunos: Perde.

Professora: Quantos? (Desafiar)

[Os alunos não conseguem responder.]

(Transcrição do diálogo entre a professoras e os alunos, 2015).

Neste trecho, as ações da professora estão relacionadas à categoria Desafiar. Ao querer que os alunos compreendam que ganhar 8 e perder 9 é o mesmo que perder 1 , ela lança a eles esse desafio. A todo o momento, ela os pressiona para a precisão (quantos?). Ao perceber as dificuldades dos alunos, ela recorre as ações de Guiar/Apoiar, focalizando o pensamento dos alunos ao evidenciar a quantidade que ela ganhou e que ela perdeu, por exemplo, e de 
Informar/Sugerir, ao validar respostas corretas dadas pelos alunos e fornecer informações. As ações de Guiar/Apoiar e Informar/Sugerir têm o objetivo de apoiar o desafio apresentado pela professora.

Diante do desafio lançado pela professora, os alunos percebem prontamente que a menina perdeu, mas não conseguem dizer quantos ela perdeu. Nesse momento começam a fazer conjecturas ("Acabou por perder 9", "se o 9 é maior que o 8, ela tinha que ficar com zero"; "ficou com 1"). Neste momento, a professora opta por delinear um novo caminho, partindo da quantidade que a menina tinha no início do jogo:

Professora: Ela tinha 7, a menina tinha 7 [indica o 7 do início do jogo]. Se a menina tinha 7 [anota o 7 no quadro], ganhou quantos? (Guiar/Apoiar) Alunos: 8.

Professora: Ganhou 8 [circula o +8 ] (Informar/Sugerir). Tinha 7 e ganhou 8. (Guiar/Apoiar). Com quanto ela ficou? Como é que eu escrevo? (Desafiar).

[Os alunos não respondem.]

Professora: Ela tinha 7 de início e ganhou 8 [registra $7+8$ ]. O que vai agora acontecer? (Guiar/Apoiar).

Alunos: Dá quinze. [a professora anota o 15.]

Professora: Ela tinha 7, ganhou 8 e ficou com 15. (Informar/Sugerir). Agora ela perdeu 9. (Guiar/Apoiar).

Alice: Menos 9 ela só fica com 6.

Dario: Fica com 6. 15 menos 9 dá 6.

Professora: Vai lá à tabela fazer o 15 menos 9 [diz para Dario]. (Guiar/Apoiar).

[Alguns alunos vão até a tabela do 100 e fazem contagem regressiva de 9 a partir do 15, chegando no 6].

Professora: O 15 tira 9 fica com quanto? (Guiar/Apoiar).

Alunos: 6.

Professora: Fica com 6. Anota ai. (Informar/Sugerir).

[Dario anota $15-9=6$ ].

Professora: Explica lá essa parte. Por que começamos do 7, Dario? (Guiar/Apoiar).

Dario: Porque é o número que ela tinha no início.

Professora: Ela começou do 0? (Guiar/Apoiar).

Alunos: Não.

Miguel: Ela começou do 7.

Professora: Depois, ao longo das quatro jogadas, o que aconteceu? (Guiar/Apoiar).

Alunos: Ganhou mais 8.

Professora: Ganhou 8. (Informar/Sugerir). Então ficou com quantos? (Guiar/Apoiar).

Alunos: 15.

Professora: E depois? (Guiar/Apoiar).

Dario: Depois perdeu 9, então teve que tirar menos 9, que deu 6.

Professora: Isso mesmo, acabou por ficar com 6. (Informar/Sugerir). Olhem lá [indica o início do jogo], se ela tinha 7 no início e acabou com 6, o que aconteceu? (Desafiar)

Paulo: Se tirar menos 1 ao 7 fica 6.

Professora: Então diz lá Paulo, para toda a gente. (Guiar/Apoiar)

Paulo: Se tirar 1 ao 7 fica com 6.

Professora: Isso mesmo. Então o que quer dizer ganhar 8 e perder 9 [indica +8 e -9$]$ é perder quantos? (Desafiar)

\footnotetext{
${ }^{2}$ A tabela a que a professora se refere é um cartaz fixado ao lado do quadro negro composto por 10 linhas e 10 colunas, com os números naturais de 1 a 100 dispostos em ordem crescente, designado Tabela do 100.
} 
Paulo: Um só.

Professora: É perder?

Alunos: 1.

(Transcrição do diálogo entre a professora e os alunos, 2015).

Ao propor aos alunos outra maneira de pensar sobre a questão, a professora realiza ações de Informar/Sugerir. Além de fornecer uma estratégia de resolução diferente, ela, a todo o momento, valida as respostas corretas dos alunos. Ainda com o intuito de conduzir o pensamento dos alunos, ela recorre a várias ações de Guiar/Apoiar, faz questionamentos que conduzem o pensamento do aluno, focaliza o pensamento do aluno para fatos importantes, como, por exemplo, questionar se a menina tinha começado do zero.

Enfim, os alunos conseguem responder ao desafio proposto pela professora. Para tanto, os alunos evidenciaram o processo de raciocínio de Comparar, ou seja, olharam para a quantidade 7, que a menina tinha no começo, e para a quantidade $6 \mathrm{com}$ a qual ela terminou o jogo, entendendo que ela perdeu 1. Usando essa informação, concluíram que, durante o jogo, ela ganhou 8 e perdeu 9, ou seja, perdeu 1, que era o objetivo da professora. Na sequência, a professora continua a discussão da tarefa, agora sobre as jogadas do menino. As discussões são muito semelhantes, as ações desempenhadas por ela também, não trazendo informações novas.

\subsection{Turma do $3 .^{\circ}$ ano-Tarefa 2}

Também nesta turma os alunos resolveram primeiro a tarefa (Figura 2) em trabalho autônomo, organizados em pares. A professora começa a discussão coletiva chamando algumas crianças para a lousa para mostrarem como resolveram a tarefa:

Professora: Marta, quer ir ao quadro fazer a primeira e explicar? Para a segunda, pode ir o João. (Convidar)

[Marta registra no quadro $13=2 \times 5+1 \times 2+1 \times 1$.]

Professora: Vamos ouvir a Marta explicar. (Convidar)

Marta: Primeiro fiz $2 \times 5$ que era 10, depois $1 \times 2$ que era $2,10+2$, e depois mais 1 , que é $1 \times 1$.

Professora: Me diz o que você esteve a fazer com esse número. (Convidar)

Marta: Decompor.

Professora: Decompor o 13, não é? (Guiar/Apoiar)

[João vai à lousa.]

João: Já posso?

Professora: Já. O João, fala lá o que vais fazer. (Convidar)

João: Eu fiz $1 \times 5$ que é 5 , fiz $4 \times 2$ que era 8, e depois pus o 0. Aqui, aqui tem 0, mais $2 \times 4$ mais 5 dava 13 .

[Outros alunos se manifestam dizendo que fizeram de maneira diferente.]

Luís: Nós fizemos $1 \times 5,2 \times 2,4 \times 1$. Porque $1 \times 5$ é 5 e $2 \times 4$ é 8 , soma 5 com 8 dá 13 [o aluno fala de seu lugar, não vai ao quadro]. 
Professora: Tudo bem, mas você está a dizer que o do João está mal? (Convidar) Luís: Não, mas há outras formas.

Professora: De que outras formas vocês fizeram? Quem é que tem uma forma diferente? Então vamos apresentar outras formas diferentes. Paulo. Diz lá em voz alta. (Guiar/Apoiar)

Paulo: Nós fizemos $1 \times 5$ que é igual a 5, $2 \times 2$ que é igual a $4,4 \times 1$.

Professora: E quanto é que isso deu? (Convidar)

Paulo: 13

Professora: Agnaldo, fez uma diferente? (Guiar/Apoiar)

Agnaldo: Sim.

Professora: Vamos ouvir. (Convidar)

Agnaldo: $1 \times 5$ que é igual a 5, $3 \times 2$ que é 6 mais $2 \times 1$.

Aluno: Eu tenho outra!

Professora: Diz lá Fábio! (Convidar)

Fábio: $1 \times 5+5 \times 2+3 \times 1$.

Professora: Pode ser?(Desafiar)

Alunos: Não.

Professora: Por que? Diz lá Paulo. (Desafiar)

Paulo: Porque ele fez $5+10$.

Professora: Ele põe $1 \times 5$ e depois, o que diz lá? (Guiar/Apoiar)

Paulo: Diz que mais $5 \times 2$.

Professora: $5 \times 2$ são 10. Mais $1 \times 5$ ? (Guiar/Apoiar)

Alunos: Dá 15.

Professora: Está com 15 já. Não dá, pois não?(Guiar/Apoiar)

Alunos: Não.

Professora: Eduardo, tem uma? (Guiar)

Eduardo: $1 \times 5$ mais $1 \times 2$ mais $6 \times 1$.

Professora: tem mais alguma coisa diferente para dizer?

Alunos: Não.

(Transcrição do diálogo entre a professora e os alunos, 2016).

Neste trecho, muitas ações da professora são de Convidar, seja solicitando aos alunos que relatem como fizeram, seja mantendo-os inseridos na discussão. Outras vezes solicita respostas para questões pontuais e que relatem as várias formas como resolveram a tarefa, ações de Guiar/Apoiar. Ao se deparar com uma estratégia inválida, a professora encoraja os alunos a avaliarem a sua validade e, em seguida, questiona os alunos sobre o porquê de não ser válida. Tais ações se enquadram em Desafiar. Para que os alunos consigam responder ao desafio (justificar por que não é válida), a professora executa ações de Guiar/Apoiar.

Com relação aos processos de raciocínio, as estratégias de resolução da tarefa apresentada pelos alunos constituem conjecturas elaboradas por eles que foram sendo validadas ou não à medida em que eram apresentadas. Para validar ou não uma estratégia, os alunos recorreram a justificativas, explicando porquê eram válidas ou não, como por exemplo, o relato de Luís "Nós fizemos $1 \times 5,2 \times 2,4 \times 1$. Porque $1 \times 5$ é 5 e $2 \times 4$ é 8 , soma 5 com 8 dá 13”, que, para além de relatar o procedimento usado, justifica porque ele era válido.

A professora segue com a discussão no quadro, agora com a parte da tarefa que 


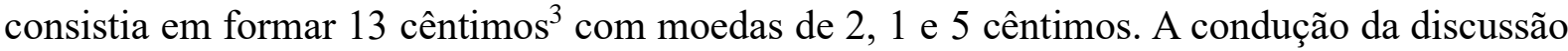
pela professora é a mesma descrita no início da tarefa, ela chama alguns alunos ao quadro para registrar e relatar como fizeram. Não há diversidade de ações executadas por ela, além de Convidar. A discussão segue agora com a segunda parte da tarefa que consistia em formar 26 cêntimos a partir de moedas de 1,2 e 5 cêntimos.

Professora: Agora o João vai apresentar sua estratégia. (Convidar)

[João vai à lousa e registra $26=4 \times 5+2 \times 2+2 \times 1$.]

João: 4 vezes 5 dá 20 . Depois eu fiz $2 \times 2$ dá 4 mais $2 \times 1$ que é 2 dá 6 , dá 26 .

Alguns alunos: Nós não fizemos igual.

Professora: João, quando te entreguei a ficha tu disseste, olhastes para a ficha e tu dissestes que há uma relação qualquer com a outra ficha. (Guiar/Apoiar)

João: Então o 26 é o dobro, 2 vezes o 13 e 13 é metade de 26.

Professora: E quando tu fostes fazer agora esse elas estão também relacionadas com as anteriores? (Desafiar)

João: Com o 13?

Professora: Sim. Do $4 \times 5$, do $2 \times 2$, do $2 \times 1$. O que é que é isso? (Desafiar)

[Como João não consegue responder, a professora continua.]

Professora: Elas são o quê ao 13? Vamos ver o que tu achas. O que é que nós temos ali naquela sequência que podemos relacionar com o 13? (Guiar/Apoiar)

Aluno: $\mathrm{O} 4 \mathrm{em} \mathrm{2,} \mathrm{o} 2 \mathrm{em} 1 \ldots$

João: Fazemos assim, esse 2 é 1 [referindo-se ao multiplicando da multiplicação $2 \times 1$ ], esse 2 é 1 [referindo-se ao multiplicando da multiplicação $2 \times 2$ ] e o 4 é 2 [referindo-se ao multiplicando da multiplicação $4 \times 5]$.

Professora: Quer dizer que temos as... (Guiar/Apoiar)

Alunos: Metades.

Professora: E ali temos o quê?? (Guiar/Apoiar)

Alunos: Os dobros.

(Transcrição do diálogo entre a professoras e os alunos, 2016).

O trecho anterior evidencia as ações da professora de Convidar em que ela, mais uma vez, solicita que os alunos relatem como resolveram a tarefa. Ao questionar João a respeito de um comentário feito por ele ao receber esta tarefa, na qual percebeu alguma relação com a tarefa anterior, focaliza o pensamento do aluno para um fato importante, ação esta de Guiar/Apoiar. Em seguida, diante da resposta de João, ela lança um desafio, que é estabelecer alguma relação entre a decomposição de 13 e de 26 em moedas de 1,2 e 5 cêntimos, encorajando o aluno a refletir a respeito desta questão. Tal ação é de Desafiar. O aluno não consegue responder prontamente, o que leva a professora a realizar, novamente, ações de Guiar/Apoiar, conduzindo o pensamento do aluno.

O aluno tinha reparado na relação de dobro e metade entre 26 e 13, mas não conseguiu, num primeiro momento, perceber que a decomposição de 26 em $4 \times 5+2 \times 2+2$ $\times 1$, lembrando que 5, 2 e 1 representam as moedas, se relacionava com a decomposição de 13

\footnotetext{
3 A moeda usada em Portugal é o Euro. A circulação de moedas de 1, 2 e 5 cêntimos (correspondente a "centavos") de Euro é comum, portanto a tarefa faz sentido na realidade portuguesa.
} 
em $2 \times 5+1 \times 2+1 \times 1$. A partir do desafio lançado pela professora, o aluno foi capaz de enunciar essa relação, evidenciando os processos de raciocínio matemático de identificar um padrão (dobro/metade) e de estender esse conhecimento para a decomposição a partir da comparação entre as expressões.

A professora dá seguimento à discussão:

Professora: Quem é que tem outra forma? (Convidar)

Ricardo: Eu fiz diferente.

Professora: Diz lá Ricardo. Traz a tua folha. (Convidar)

[Ricardo começa a fazer o registro na lousa.]

Ricardo: Então, eu fiz de uma maneira diferente. Primeiro fui fazer 2 vezes 5, duas vezes moedas de 5 cêntimos davam 10 cêntimos, depois fiz esse cálculo outra vez, só que ao contrário, com moedas de 2 cêntimos (referindo-se a $5 \times 2$ ), já tinha 20 cêntimos, mais 6 cêntimos que é $6 \times 1$, dava 26 .

Professora: Dava 26. (Informar/Sugerir). E tem ai algum cálculo do 13 que esteja relacionado? (Desafiar)

Bento: Sim.

Professora: Qual é Bento? (Guiar/Apoiar)

Bento: É aquele do $2 \times 5$ que dava 10, depois $1 \times 2$ e depois $1 \times 1$.

Professora: Mas parece que se relaciona com o que? (Guiar/Apoiar)

Ricardo: Com o último. Aquele último que nós fizemos, a última parte, era metade. [referindo-se a $13=5 \times 2+3 \times 1$ ].

Professora: Era $3 \times 1$ e passou agora ao... (Guiar/Apoiar)

Alunos: $6 \times 1$.

Professora: Que é o quê? (Guiar/Apoiar)

Alunos: Dobro.

Professora: Temos o dobro de 3 e depois temos $5 \times 2$, o que acontece com aquela multiplicação do $5 \times 2$ ? Temos ali $5 \times 2+3 \times 1$. No 26 temos $2 \times 5+5 \times 2$. O que tivemos que fazer? (Desafiar)

[Os alunos não respondem.]

Professora: Temos ali $5 \times 2$, 10, e aqui temos $2 \times 5+5 \times 2$. Por quê? (Desafiar)

Luis: Porque $2 \times 5$ é 10, então nós temos que acrescentar mais 10 .

Professora: Então por que eles estão relacionados? Justifica aí. (Desafiar)

[Os alunos não respondem.]

Professora: $5 \times 2$ são 10 e o que eu tenho que fazer? (Desafiar)

Ricardo: Tenho que fazer 2 vezes este. $2 \times 5$ ou $5 \times 2$.

Gustavo: Também dá, num dos cálculos a seguir, para juntar esses e fica com $4 \times 5$.

Professora: Também dava por $4 \times 5$, muito bem! (Informar/Sugerir). Se multiplicasse por 4 seria o quê? (Desafiar)

Gustavo: Seria o dobro.

Professora: Exatamente. (Informar/Sugerir).

(Transcrição do diálogo entre a professoras e os alunos, 2016).

Com a finalidade de levar os alunos a identificarem múltiplas estratégias de resolução, a professora incentiva-os a relatarem outros modos de fazer, compartilhando-os com os demais alunos da turma, ações de Convidar. Também, a professora valida e reelabora respostas corretas fornecidas pelos alunos, ações de Informar/Sugerir. Com relação a Desafiar, a professora desafia os alunos sobre a relação entre a decomposição de 13, já feita por eles, e a de 26, agora na resolução apresentada por Ricardo. Em seguida ela recorre às 
ações de Guiar/Apoiar, conduzindo e focalizando o pensamento dos alunos, até que eles consigam responder ao desafio.

Ricardo identifica, num dos cálculos que já tinha sido feito, que $3 \times 1$ usado na decomposição de 13 passou a ser $6 \times 1$ na decomposição de 26 , entretanto, ele mesmo afirma ser a "última parte" que era metade. A professora chama a atenção para a multiplicação $5 \times 2$ usada em $13=5 \times 2+3 \times 1$ e em $26=2 \times 5+5 \times 2+6 \times 1$, perguntando porquê. Deste modo, a professora solicita que os alunos apresentem razões e, na sequência, alguns apresentam justificativas para a questão, recorrendo a conhecimentos matemáticos anteriores, a saber, as propriedades da multiplicação.

\section{Discussão}

O presente estudo tinha como objetivo analisar as ações realizadas por duas professoras que atuam nos primeiros anos do $1^{\circ}$ Ciclo de Ensino Básico em Portugal durante a discussão de tarefas selecionadas para apoiar o desenvolvimento do raciocínio matemático. Nas duas turmas foi possível perceber as ações das professoras distribuídas nas quatro categorias de análise apresentadas por Araman, Serrazina e Ponte (2019). Com relação a Convidar, as ações das professoras, em ambas as turmas, tinham como objetivo inserir os alunos na discussão (PONTE; MATA-PEREIRA; QUARESMA, 2013). Estas ações, embora não apresentem forte potencial para o raciocínio matemático, são necessárias como passo prévio para ações das demais categorias. $\mathrm{Na}$ categoria Guiar/Apoiar, as ações realizadas tinham como objetivo conduzir o pensamento do aluno, focalizar o seu pensamento para fatos importantes e fornecer-lhe pistas.

Estas ações permeiam toda a discussão, pois partem de questões pontuais e evoluem ao longo da discussão, conduzindo o pensamento dos alunos para onde a professora deseja (ELLIS; ÖZGÜR; REITEN, 2018). Por exemplo, na turma do $1^{\circ}$ ano, a professora chama a atenção dos alunos para o número de jogadas e a quantidade de berlindes que a menina ganhou ou perdeu em cada uma delas. Já na turma do $3^{\circ}$ ano, a professora faz uma sequência de questionamentos que conduzem os alunos a repararem na relação de dobro/metade entre 13 e 26. Embora tais ações, por si só, não originem diretamente processos de raciocínio, muitas delas contribuíram para que os alunos pudessem responder aos desafios propostos pela professora. Fato semelhante ocorre com Informar/Sugerir. As ações desta categoria estão presentes nas duas turmas.

As estratégias de condução da discussão das tarefas por parte das professoras são 
diferentes. Na turma do $1^{\circ}$ ano, as ações da professora estão muito relacionadas com a validação e a repetição das respostas corretas dadas pelos alunos, havendo também momentos em que ela fornece informações, por exemplo, quando diz que o rapaz também começou com mais, e fornece outra estratégia de resolução, ao propor outra maneira de se pensar sobre a questão, começando por 7, que a menina tinha no início do jogo. Na turma do $3^{\circ}$ ano, as ações da professora estão mais centradas em incentivar os alunos a apresentarem outras estratégias de resolução, ou seja, permitir que os alunos tenham contato com outros modos de fazer e pensar.

As ações de Desafiar apresentam alto potencial para promover o raciocínio matemático (ELLIS; ÖZGÜR; REITEN, 2018), pois auxiliam os alunos a justificarem seu pensamento, oferecendo razões que o fundamentam. Estas ações estiveram presentes nas duas turmas. Por exemplo, na turma do $1^{\circ}$ ano, a professora propõe um desafio ("Por que isso acontece?"), ao se referir à quantidade de berlindes, em ordem inversa, da menina e do menino (7 e 12 e 12 e 7). Ao perguntar o porquê, a professora incentiva os alunos a apresentarem razões, ou seja, justificar sua resposta, o que aconteceu com alguns alunos. Assim, as suas ações conduziram ao processo de justificar, como definido por Jeannotte e Kieran (2017).

Na sequência da discussão, a professora lança outro desafio, ao querer saber quanto é ganhar 8 e perder 9. Os alunos fazem algumas conjecturas ("tinha que ficar com 0", "ficou com 1"). Como indicam Morais, Serrazina e Ponte (2018), as conjecturas são declarações que necessitam ser examinadas para sua validação ou não. No caso, ao longo da discussão, os alunos foram percebendo que algumas das conjecturas que apresentaram não eram válidas. Mas tal percepção é baseada pelas ações da professora. Ao notar a dificuldade dos alunos em responder ao desafio, a professora apresenta um novo modo de olhar para a questão, partindo da quantidade 7 de berlindes que a menina tinha no início do jogo e na quantidade 6 com a qual terminou. Os alunos concluíram que, ao final do jogo, consideradas todas as jogadas, ela perdeu $1 \mathrm{e}$, num processo de comparação, também mediado pela professora, conseguiram responder ao desafio (ganhar 8 e perder 9 é o mesmo que perder 1). Os alunos usaram um conhecimento que tinham $(7-1=6)$ para construir novo conhecimento $(8-9=-1)$, evidenciando a presença de raciocínio matemático, subsidiado pelo processo de comparar.

Também na turma do $3^{\circ}$ ano, são apresentadas várias estratégias de resolução dos alunos. Ao elaborar uma estratégia, os alunos formularam conjecturas, mesmo que de forma inconsciente, pois, ao definirem um procedimento a usar, consideraram que este caminho os conduziria a um resultado. À medida que foram apresentadas, tais estratégias foram sendo 
validadas ou não por meio de justificativas apresentadas pelos alunos. Ao justificar, os alunos apresentam razões pelas quais elas são válidas ou não, ou seja, alteram seu valor epistêmico (ARAMAN; SERRAZINA; PONTE, 2019). Em outro momento, a professora lança o desafio a respeito da relação de metade/dobro entre 13 e 26 e em suas decomposições. Para responder ao desafio, os alunos recorrem a conhecimentos que já possuíam (13 é metade de 26 e propriedades da multiplicação) e, por meio da comparação entre as expressões, conseguem perceber que esta relação também está presente nas decomposições de 13 e de 26. Neste caso temos evidência de raciocínio matemático suportado pelo processo de comparar.

\section{Conclusão}

Concluímos este estudo destacando a importância das ações das professoras no desenvolvimento do raciocínio matemático dos alunos. As ações e as combinações de ações realizadas pelas professoras levaram os alunos a raciocinarem matematicamente. As ações de Convidar levam os alunos a darem indicações sobre o modo como resolveram as tarefas. Tais ações não conduziram ao raciocínio matemático, porém, elas iniciaram o envolvimento dos alunos na discussão. As ações de Guiar/Apoiar e de Informar/Sugerir conduziram os alunos a formularem estratégias de resolução, identificar um padrão, elaborar conjecturas e comparar. Essas ações combinadas deram suporte a processos de raciocínio mais elaborados que ocorreram a partir das ações de Desafiar.

Os questionamentos feitos pelas professoras nas ações de Desafiar abriram mais possibilidades de raciocínio matemático, levando os alunos a apresentarem justificativas para seus modos de pensar e resolver a tarefa, num processo de validação. É de notar que, nas duas turmas, os processos de raciocínio evidenciados na categoria Desafiar não ocorreram de forma isolada, mas são consequências das diversas ações das demais categorias realizadas pelas professoras ao longo da discussão. Ou seja, as justificativas apresentadas pelos alunos foram suportadas pelos processos de raciocínio desencadeados a partir de combinações de ações dos diversos tipos. Deste modo, os resultados alcançados por este estudo trazem evidências da relevância que as diferentes ações dos professores têm para o desenvolvimento do raciocínio matemático e do modo como essas ações abrem possibilidades para processos de raciocínio matemático desde os primeiros anos. 


\section{Agradecimentos}

As tarefas aqui apresentadas foram elaboradas no âmbito do projeto Pensamento numérico e cálculo flexível: Aspectos críticos desenvolvido por docentes das Escolas Superiores de Educação de Lisboa, Setúbal e Portalegre. Agradecemos à Capes pelo apoio recebido pela primeira autora na realização desta pesquisa, por meio do Programa PVEx (Programa de Professor Visitante no Exterior)/Processo nº 88881.170306/2018-01.

\section{Referências}

ARAMAN, E. M. O.; SERRAZINA, M. L.; PONTE, J. P. "Eu perguntei se o cinco não tem metade": ações de uma professora dos primeiros anos que apoiam o raciocínio matemático. Educação Matemática Pesquisa, São Paulo, v. 21, n. 2, p. 466-490, 2019.

BRUNHEIRA, L.; PONTE, J. P. Justificando generalizações geométricas na formação inicial de professores dos primeiros anos. Bolema, Rio Claro, v. 33, n. 63, p. 88-108, abr. 2019.

COBB, P.; JACKSON, K.; DUNLAP, C. Design research: an analysis and critique. In: ENGLISH, L. D.; KIRSHNER, D. (Ed.). Handbook of international research in mathematics education. New York: Routledge, 2016. p. 481-503.

ELLIS, A.; ÖZGÜR, Z.; REITEN, L. Teacher moves for supporting student reasoning. Mathematics Education Research Journal, Melbourne, v. 30, n. 2, p. 1-26, jun. 2018.

JEANNOTTE, D.; KIERAN, C. A conceptual model of mathematical reasoning for school mathematics. Educational Studies in Mathematics, Dordrecht, v. 96, n. 1, p. 1-16, 2017.

LANNIN, J.; ELLIS, A. B.; ELLIOTT, R. Developing essential understanding of mathematical reasoning for teaching mathematics in prekindergarten - grade 8. Reston: National Council of Teachers of Mathematics, 2011.

MATA-PEREIRA, J.; PONTE, J. P. Enhancing students' mathematical reasoning in the classroom: teacher actions facilitating generalization and justification. Educational Studies in Mathematics, Dordrecht, v. 96, n. 2, p. 169-186, 2017.

MATA-PEREIRA, J.; PONTE, J. P. Promover o Raciocínio Matemático dos Alunos: uma investigação baseada em design. Bolema, Rio Claro, v. 32, n. 62, p. 781-801, 2018.

MORAIS, C.; SERRAZINA, L.; PONTE, J. P. Mathematical reasoning fostered by (fostering) transformations of rational number representations. Acta Scientiae, Canoas, v. 20, n. 4, p. 552-570, 2018.

NCTM. Focus in high school mathematics: Reasoning and sense making. Reston: NCTM, 2009.

PONTE, J. P.; CARVALHO, R.; MATA-PEREIRA, J.; QUARESMA, M. Investigação baseada em design para compreender e melhorar as práticas educativas. Quadrante, Lisboa, v. 25, n. 2, p. 77-98, 2016.

PONTE, J. P.; MATA-PEREIRA, J.; QUARESMA, M. Ações do professor na condução de discussões matemáticas. Quadrante, Lisboa, v. 22, n. 2, p. 55-81, 2013. 
PONTE, J. P.; MATA-PEREIRA, J.; HENRIQUES, A. O raciocínio matemático nos alunos do ensino básico e do ensino superior. Práxis Educativa, Ponta Grossa, v. 7, n. 2, p. 355-377, jul./dez. 2012.

PONTE, J. P.; QUARESMA, M. Teachers' professional practice conducting mathematical discussions. Educational Studies in Mathematics, Dordrecht, v. 93, n. 1, p. 51-66, 2016.

STYLIANIDES, G. J. Reasoning-and-proving in school mathematics textbooks. Mathematical Thinking and Learning, London, v. 11, n. 4, p. 258-288, 2009.

WOOD, T. Creating classroom interactions for mathematical reasoning: beyond "natural teaching". In: ABRANTES, P.; PORFÍRIO, J.; BAÍA, M. (Org.). The interactions in the mathematics classroom: proceedings of the CIEAEM 49. Setúbal: Escola Superior de Educação, 1997, p. 34-43.

Submetido em 28 de Outubro de 2019. Aprovado em 29 de Março de 2020. 